\title{
Erratum to: The Attitude of Psychiatric and Non-psychiatric Health-care Workers Toward Suicide in Malaysian Hospitals and Its Implications for Training
}

\author{
Ching Sin Siau ${ }^{1}$ - Lei-Hum Wee ${ }^{1}$ - Sapini Yacob ${ }^{2} \cdot$ Seen Heng Yeoh ${ }^{3}$. \\ Tassha Hilda binti Adnan ${ }^{4}$ Jamaiyah Haniff ${ }^{4}$ Komathi Perialathan ${ }^{5}$. \\ Aziman Mahdi ${ }^{5}$ Abu Bakar Rahman ${ }^{5}$ Choon Leng Eu ${ }^{6} \cdot$ Suzaily binti Wahab ${ }^{6}$
}

Published online: 9 August 2017

(C) Academic Psychiatry 2017

Erratum to: Acad Psychiatry

DOI 10.1007/s40596-017-0661-0

The Funding Sources section should read as follows:

This study was funded by a grant from the Ministry of Health, Malaysia (Grant No.: 01068) and the National University of Malaysia Research University Grant (GUP-2014-065). The funding agencies had no role in the study design, data collection, data analysis, manuscript writing, or publication.

The online version of the original article can be found at http://dx.doi.org/ 10.1007/s40596-017-0661-0

Lei-Hum Wee

weeleihum@gmail.com

National University of Malaysia, Kuala Lumpur, Malaysia

2 Hospital Putrajaya, Ministry of Health, Putrajaya, Malaysia

3 Universiti Tunku Abdul Rahman, Kajang, Selangor, Malaysia

4 National Clinical Research Centre, Ministry of Health, Kuala Lumpur, Malaysia

5 Institute for Health Behavioral Research, Ministry of Health, Kuala Lumpur, Malaysia

6 National University of Malaysia Medical Centre, Kuala

Lumpur, Malaysia 